NASA Technical Memorandum 82815

(AIAA PAPER 82-0320)

\title{
The Role of Modern Control Theory in the Design of Controls for Aircraft Turbine Engines
}

J. Zeller, B. Lehtinen, and W. Merrill Lewis Research Center Cleveland, Ohio

Prepared for the

Twentieth Aerospace Sciences Conference sponsored by the American Institute of Aeronautics and Astronautics Orlando, Florida, January 11-14, 1982
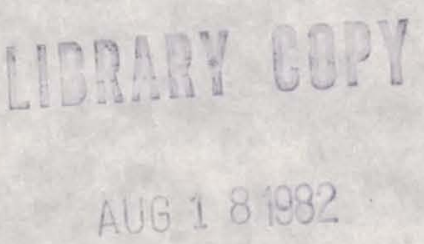
THE ROLE OF MOOERN CONTROL THEORY IN THE DESIGN OF CONTROLS FOR AIRCRAFT TURBINE ENGINES

\author{
J. Zeller, B. Lehtinen and W. Merrill \\ Lewis Research Center \\ Cleveland, Ohio
}

\section{Abstract}

The paper discusses what has been accomplished over the last ten years in applying "Modern Control Theory" to the design of controls for advanced aircraft turbine engines. The results of successful research programs are discussed. Ongoing programs as well as planned or recommended future thrusts are also discussed.

\section{Introduction}

In its early years the aircraft turbine engine control system performed a rather simple task. The task was to meter the fuel to the combustor at the proper fuel-to-air ratio for both transient and steady-state operating conditions. Over the years, however, things have changed significantly. To achieve more thrust for less weight and to improve specific fuel consumption, many additional manipulated inputs have been added to the aircraft powerplant. Figure 1 shows the trend in complexity that has occurred over the years. Noted on this figure are a number of operational engines which have been put into service. The new control inputs include such things as variable compressor inlet guide vanes, variable compressor stators, variable exhaust nozzle area etc.

The task of selecting a control algorithm for an engine with an increased number of inputs now becomes a formidable problem. Traditional singleinput/single-output techniques can be used for the now multi-input/multi-output problem. They are, however, inadequate and require many judgemental interactions to even get close to a suitable engine control law. The designer would really like a direct and straightforward method for handling the multivariable problem. This procedure should be able to eliminate unwanted interactions between different variables while bringing into play those interactions which are favorable. Faced with these needs, the propulsion control community began in the early 1970 's to investigate what new methodology was available to satisfy those needs. This investigation led them to a new control methodology termed "Modern Control Theory" (MCT).

This paper is intended to describe what has been accomplished by applying MCT to the propulsion control design problem over the last ten or so years and what work yet remains to be done. This description will be organized as follows. First, there will be a brief discussion of the evolution of control design methodology. This will be followed by a description of the problems which must be faced in applying MCT to the propulsion control design task. The past accomplishments of the last ten or so years in applying MCT to propulsion control will be the subject of the next and most detailed section of the paper. Finally, the ongoing activities and planned and recommended future thrusts will be discussed.
Multivariable Propulsion Control Design

Evolution of Control Design Methodology

About 1960, control theoreticians began to recognize that Linear Systems Theory (which had been around for a long time) could possibly be used in the closed-10op control design process for large complex physical processes. At the same time computers which could easily solve the numerical problems associated with large linear system problems were rapidly evolving and becoming readily accessible to larger numbers of users. Thus began the era of "Modern Control Theory". This terminology was used to differentiate the new methods from the traditional linear system single-input/single-output (SISO) frequency domain design methods in widespread use at that time. These traditional methods employed such tools as: Nyquist diagrams, Bode plots, root locus plots, etc. Refs. G2 and G6 are representative of the many texts describing the traditional methods.

Prior to the era of MCT when a designer was faced with designing a control for a complex, multi-input/multi-output (multivariable) physical process, the approach was as follows. The designer would first put together an analytical representation of the physical process to be controlled. This analytical model usually consisted of a number of algebraic and differential equations. In most cases, these equations are nonlinear. To use the available linear methods, the family of nonlinear describing equations would be linearized about one or more process operating points. Then for each linear model one of the frequency domain SISO design methods mentioned earlier could be used one loop at a time. If the results were not satisfactory, this loop-at-a-time design was done iteratively in a sort-of trial and error process to eventually produce a satisfactory multivariable control. In those cases where more than one linear operating point model was needed to describe the process this complex iterative procedure would have to be done for each operating point. Finally, the resulting family of linear controllers would have to be tied together in some manner.

The new MCT techniques for multivariable systems were based upon a matrix formulation of the large number of differential equations describing the process. Two distinct schools of thought began to emerge. The approach most popular in this country formulated the problem directly in the time domain and is commonly referred to as the "state space formulation". Prominent contributors to the early growth of time domain methods were Kalman, and Athans and Falb (Refs. G4 and G1). One of the most popular of the time domain methods was the Linear Quadratic Regulator (LQR) method. Ref. G3 contains a comprehensive bibliography of $L Q R$ activities and contributions. Many of the first applications involved flight controls, space vehicle guidance and some industrial process controls. In addition, a 
large number of purely analytical endeavors and numerous doctoral dissertations were produced, most of which are tabulated in Ref. G3.

The second school of thought which also can be categorized under "Modern Control Theory" had its origins in Great Britain. It retained the frequency domain formulation of the describing equations but extended the methodology to cover multivariable systems. Methods such as the Inverse Nyquist Array and Characteristic Locus by such contributors as Rosenbrock and McFarlane (Refs. G7 and G5) were put into practice.

\section{Propulsion Control Design Problems}

The multi-input aircraft turbine engines being designed in the early 1970's could be modeled analytically by a set of nonlinear algebraic and differential equations. In addition, many of the elements such as compressors, fans, and turbines did not lend themselves easily to closed-form analytical expressions. This posed the first major problem for control designers bent upon applying all this useful linear multivariable theory. Linearization of the engine model at a number of operating points was not easy to do analytically. In most cases a set of linear engine models could only be obtained by perturbing the large dynamic digital engine simulations developed by the engine manufacturer. The second problem was the lack of mature computational aids needed to solve large problems in multivariable control using LQR or other approaches. Computeraided design packages were emerging but they were far from being easily usable or readily accessible.

The third problem arose from the fact that a lmost all the methodology of MCT in the early 1970 's required a linear system representation of the process. The propulsion process is extremely nonlinear and especially so when a large altitude Mach number operating envelope is involved. The problem that could arise would be the need to perform a large number of linear control designs all of which have to be organized into a final control law.

Nevertheless the technical community moved forward and began to evaluate the applicability of MCT to propulsion control design problems. What has been and is yet to be accomplished will now be discussed.

\section{Applications to Engine Control, 1970 to Present}

In this section, a review is made of the reports and papers appearing in the last decade which applied MCT to the turbine engine control design problem. In making this review, it is helpful to highlight eight significant meetings which were held during that time period. At these meetings (denoted in Fig. 2) turbine engine control-related results were presented and discussions held among participants which helped shape ongoing research efforts.

The first meeting (no. 1 in Fig. 2) was a seminar sponsored by the Air Force Office of Scientific Research and was held at the Air Force Wright Aeronautical Laboratory (AFWAL) in August, 1974. At this meeting G. J. Michael, then of United Technologies Research Center, and C. R. Stone of
Honeywe 11 Corporate Research presented their results in MCT (specifically LQR methods) applied to aircraft turbine engines. These two efforts, as reported in Refs. L29, L30, and L39 are regarded as foundational. One outcome of the 1974 meeting was a recommendation that a program be initiated involving an engine test of an LQR-designed control. The Air Force (AFWAL) and NASA Lewis Research Center jointly implemented this recommendation by cosponsoring the F100 Multivariable Control Synthesis Program (MVCS). This program represents a major effort and will be discussed further in a subsequent section.

The second, fourth, seventh, and eighth meetings were Joint Automatic Control Conferences (JACC). These conferences occurred yearly, but the July 1976, June 1977, August 1980, and June 1981 meetings each included a session devoted exclusively to the problems of turbine engine control. As a result many results in MCT applied to turbine engines were presented at these sessions. Additionally, these meetings afforded the presenters valuable discussions with colleagues which further stimulated work in this field.

The third meeting was the industry review of the F100 MVCS program. At this meeting, held at AFWAL in January 1977, results of the control design and computer evaluation phases of the program were presented.

The fifth meeting was the International Forum on Alternatives for Linear Multivariable Control sponsored by the National Engineering Consortium (NEC). This meeting took place in Chicago, IL on October 1977. This meeting is significant because a majority of the presentations at this conference included an application of MCT to a model of the F100 engine. This format not only allowed comparisons between different theories when applied to a practical problem but it also broadened the reported scope of engine control research.

In May 1979 the sixth meeting, the 1979 Propulsion Controls Symposium (PCS), took place at the Lewis Research Center in Cleveland, $\mathrm{OH}$. This symposium included presentations by several researchers representing government, academia and industry to assess the state-of-the-art. Also, presentations were given to determine the future needs and problem areas of propulsion control systems. A round table workshop and an open discussion session concluded the symposium and helped establish the direction of future research and the appropriate roles of government, industry, and academia.

In discussing MCT applications to turbine engine control, it is convenient to divide the work into a number of categories. For this paper, the following five categories were selected.

1. Linear Quadratic Regulator (LQR) methods.

2. Frequency Domain methods.

3. Identification, Estimation, and Model Reduction.

4. Detection, Isolation, and Accommodation.

5. Others 
For each category, dates of report or paper occurrence have been plotted on a separate time-line figure similar to Fig. 2. Each figure also includes meeting dates in order to provide a visual picture of the quantity and relative timing of the various works. To be consistent, the reference list has also been subdivided into five categories.

\section{Linear Quadratic Regulator (LQR) Methods}

The application of $L Q R$ methods to turbine engine control design is by far the most active area of modern control theory applications, with over forty papers published relating to engine control. Fig. 3 shows a time-line array of these papers for the period 1970 to the present. Seven of these papers have been selected to serve as highlights of the activity in this area and will be discussed below.

The earliest application of LQR methods to engine control was by Michael and Farrar in 1973 (Ref. L29) with subsequent work documented in Ref. L30. Under sponsorship from the Office of Naval Research, they developed a control structure for handling large signal inputs and applied their control to a simulation of the $\mathrm{F} 100$ engine at sea level static conditions. Linear models, used in the design, were developed from the simulation via a curve fitting procedure. As mentioned previously, this work was summarized at the 1974 Air Force Seminar.

Other early work included an MS thesijs L 5 by Bowles and the report by Stone et al. ${ }^{\mathrm{L} 39}$ of Honeywe11. Ref. L39 documents the design and sea level testing of an LQR-based control for the GE J-85 engine. The primary control variable was fue 1 flow, with limited control of exhaust nozzle area and scheduled compressor bleed and inlet guide vane angles. Again, this work was reported at the 1974 seminar.

In 1975, Merrill L26 documented the use of a discrete output regulator to control a simple turbojet engine simulation. He investigated further applications of the output feedback regulator to the F100 engine in Refs. L27 and L28. Other work in the 1975 time period was that at Bendix by Elliot and Seitz L17 and at AFAPL by Weinberg L43.

Weinberg, in particular, developed a now widely used procedure for generating linear state variable models from a nonlinear (F100) simulation by using perturbation techniques. He also developed an operating line control for the F100 at sea level static. Spurred on by these developments, in 1975, the F100 MVCS program was initiated.

In 1976, the first of a number of special sessions on turbine engine control was held at that year's JACC. A key paper presented there was one by Beattie and Spock 23 of Pratt and Whitney, who described an LQR control for a variable cycle engine. Although the study was conducted on a simulation at sea level static, the work was significant because it dealt with more control inputs than had previous studies. Also presented at the JACC was a paper by Slater $\mathrm{L} 37$ on the use of integrators in an LQR engine control and one by DeHoff and Hall L on the preliminary results of the F100 MVCS program (a related paper by DeHoff and Hall is Ref. L8). The complete results of the design and simu- lation evaluation phase of the MVCS program were presented at the January 1977 F100 Industry Review.

As previously indicated, the F100 MVCS program was a jointly-funded effort which attempted to demonstrate that LQR theory could be successfully applied to design a practical engine control. A control law capable of operating an F100 over its complete flight envelope was designed under contract by Systems Control, Inc. The control laws were implemented by NASA Lewis on a minicomputer and used to control a real-time hybrid F100 simulation. The control was extensively evaluated on the hybrid and the results of both the design process and hybrid evaluation reported at the Industry Review. The information presented there is documented in SCI's final report $L 10$ and also in a NASA report by Szuch et al. L41. In addition, Refs. L9, L11, L13, L14, L15, and L36 document various detailed aspects of the MVCS program. Partially as a result of the MVCS program, a special NEC forum was held in 1977. At the forum, various alternative methods for designing multivariable controls for a typical turbine engine were compared and contrasted. The F100 engine at sea level static, intermediate power condition was chosen as the theme problem. At the forum, seven papers were presented which used some type of LQR method to design an F100 control (Refs. L18 to 21 and L28, for example). While only the linear regulator portion of the control system was addressed, much valuable insight into the application of multivariable theories was gained and the importance of aircraft turbine engine control problems was conveyed to a wide audience of control theorists.

As a result of the success of the F100 MVCS program, AFAPL initiated a program involving SCI and GE Evendale directed at designing a control for a $G E$ variable cycle engine using LQR theory. Ref. L42 by Wanger et al. of GE documents preliminary results of the program. Multivariable control design results were reported by Rock and DeHoff of SCI in Ref.L32. The general control structure for the VCE was a refinement of that developed by SCI for the F100 MVC. Additional details of the design were documented in 1978 in Refs. L2 and L12. At the present time, an evaluation of the control is being conducted using a detailed nonlinear variable cycle engine simulator.

Further developments in applied LQR theory were presented at the 1979 Propulsion Control Symposium held at NASA Lewis. Papers included one on integrated inlet/engine control L4, the GE/SCI VCE program (L33) and an overview of the results of the altitude test phase of the F100 MVCS program L22.

The altitude tests of the F100 MVC were conducted at NASA Lewis during 1978. They successfully demonstrated that the MVC logic could control an actual engine in an altitude test facility throughout the engine's normal flight envelope. The results of the tests are reviewed in a paper by Lehtinen, DeHoff, and Hackney L23 and L24. Also, details of this phase of the program are contained in Ref. L16 and in forthcoming NASA reports L25 and L 38

Continuing activity in applying LQR methods to the engine control problem is evidenced by the appearance of two LQR-related papers in a special session at the 1979 JACC. Chung and Holley L6 
extended their previous work on triangular decomposition and Rock and DeHoff L 34 discussed the use of output feedback as was used in a VCE control.

\section{Frequency Domain Methods}

Frequency domain control design methods have not been applied to the aircraft engine control problem to the same degree as have LQR methods. However, the frequency domain has been receiving increasing attention in recent years. Fig. 4 shows that over twenty reports and papers have been published since 1970 dealing with frequency domain methods applied to turbine engine control problems. Six of these papers will be highlighted in this section.

One of the earliest applications of the wellknown INA (Inverse Nyquist Array) method of Rosenbrock was to a gas turbine (McMorran, Ref, F13, 1970). A related paper by MacFarlane et.al Fl2, presented results of applying INA and Characteristic Loci to an aircraft turbine engine problem. Other than these two efforts, little else was published on engine applications in the seventies until 1976 when a paper by Sain et.al. appeared at the 1976 JACCF18. They discussed the application of MacFarlane's Characteristic Locus method to a simple turbof an engine model. This work was supported by NASA Lewis on a grant to the University of Notre Dame. Another effort begun at that time under Lewis sponsorship was work using the Multivariable Nyquist Array (MNA) by Leininger of the University of Toledo. The first results of this work were reported in $1977 \mathrm{F5}$. Geji and Sain, in 1977 F2 reported an application of matrix polynomial design techniques to engine control - a somewhat different frequency domain approach. These preliminary efforts in areas other than LQR plus the increasing interest shown by other control theorists in the turbine engine control problem led to the establishment of the 1977 NEC forum, where seven out of fourteen papers addressing the theme problem could be classified as using frequency domain techniques.

Notable among the NEC papers was one by Kouvaritakis and Edmonds F4 in which they described how both Multivariable Root Locus and Characteristic Locus techniques were used to design a three input/output controller for the F100. In addition, they considered a three input problem in which estimates of key unmeasurable variables

(thrust, airflow and turbine inlet temperature) were used as the feedback variables. Another paper, by Spang of GE F22, discussed the use of Rosenbrock's INA CAD package to obtain a diagonal-dominanceproducing compensator for both three and four input F100 designs.

Other frequency domain papers presented at the NEC were ones by Hofmann, Teper and Whitbeck F3, Leininger FG, Peczkowski and Sain F14, Rosenbrock and Munro F17 and Schafer and Sain F20. The success of these frequency domain approaches indicated that using frequency domain methods, it might be possible to develop control systems which are simpler than those produced using LQR methods. This conjecture was not substantiated at the NEC, however, since all proposed control designs were good only for one operating point and not over the full F100 operating envelope.
The next occurrence of frequency-domain-based engine control papers was at the 1979 PCS, where three papers were presented. One by Leininger F8 discussed the MNA method, in which an optimization procedure is used to achieye system diagonal dominance. Sain and Schafer fl9 described the use of so-called CARDIAD plots to map out regions in the Nyquist plane where dominance-producing compensators can exist. A key paper at this symposium was presented by Peczkowski $F 15$ describing a direct transfer matrix approach. A desired closed-loop transfer function matrix was defined and a feedback compensator computed which allowed the desired closed-loop relationship to be achieved. Peczkowski refined and extended his procedure and presented it at the 1979 JACC F16. Also, at this meeting, Schaefer and Sain F21 described a four input design for the F100 engine using CARDIAD plots.

During 1979, Leininger further elaborated his work on dominance optimization and dominance sharing at the IFAC CAD symposium $F 7$ and in Automatica and The most recent compilation of his work is a 1981 report F11 which covers the MNA design of a two input control for the GE QCSEE engine. The design was evaluated over the full engine power range at sea level static on both linear engine models and on a full nonlinear simulation.

The most recently published report on frequency domajn design applications is that by Brown of GE F1. It describes the use of MacFarlane's CLADP package to design multivariable regulators for an advanced VCE for a V/STOL aircraft. The engine is quite complex, having twelve input variables. Approximate diagonalization was achieved through use of the so-called $K / Q$ method and the resultant designs were evaluated on a nonlinear digital simulation.

\section{Identification, Estimation, and Model Reduction}

This category discusses the work accomplished in identification, estimation, and model reduction using modern control theory applied to aircraft turbine engines. The time line plot of the published papers in this category is given in Fig. 5 .

These three topics are closely related and are important to the overall engine modeling and control problem. In identification the determination of a useable parametric model for control design (typically a state space model) is the goal. In estimation, a model is required to predict the response of desired engine variables. In model reduction, the complexity of high order state space models identified from engine simulations must be reduced to a less complex, low order model, which is useable in a control design process. The following paragraphs discuss the important work in these three areas.

In the identification area three papers are highlighted. The first is by Michael and Farrar 110. In this paper an algorithm which least squares estimation and nonlinear dynamic filtering was used to identify the parameters of an F100/F401 turbofan computer model. The model was multivariable and noise was introduced to simulate 
stochastic input/output data. The multivariable model was identified from simulated stochastic input/output open loop engine data. The second highlighted paper is by R. L. DeHoff 13 . Here a single input engine model was determined from closed-loop flight data using a maximum likelihood parameter search of dynamic engine simulation parameters. It was assumed that there was no process noise and the parameter search was accomplished off-line. The final highlighted identification paper is by $W$. Merrill 19. In this work multivariable engine dynamics of an F100 engine were identified using actual closed-loop input/output engine altitude test data. Both Bill of Material (BOM) and MVC control test data histories were used on the identification process. The parameters were identified using a recursive instrumental variable approach that, although applied off-line, could be implemented in a real-time or on-line mode to continually update the model parameters as the engine test evolves. In the other identification papers a two input model was identified using the "Method of Models" in I13. This model form was used in I1 for engine condition monitoring studies. In I2, F100 engine models were determined from an engine simulation using an offset derivative approach and an output error identification technique. In I4 an equation error approach was used to obtain models of the QCSEE engine. In I7 a multivariable model for the QCSEE was obtained as a time domain realization of single-input/single-output transfer functions. The realization was constructed by retaining the system's centralized fixed modes and eliminating al others. The single-input/single-output transfer functions were identified by the extended, adjustable-parameter-vector recursive ident ification technique. In Ref. I8 a time series analysis method was used to find model structure and modelequivalent Kalman filters for a single input engine.

In the area of estimation, Michael and Farrar have authored three papers I5, I11, and I12 which essentially developed, investigated and applied a Kalman estimator/filter with model-mismatch compensation. This filter was applied to an F100/F401 turbofan engine. In I14, R. Sahgal et.al. developed a real-time F100 engine simulation which was used in conjunction with Kalman estimation to dynamically estimate high turbine and fan turbine inlet temperature in an F100 engine to improve engine protection.

In papers $16,115,116,117$, and 118 different approaches to reducing the complexity of state space models are presented. In each case, however, equilibration of high frequency modes was the operational principle of reduction.

\section{Detection, Isolation, and Accommodation}

This category describes the application of MCT to the detection, isolation, and accommodation (DIA) of sensor failures in aircraft turbine engines. The time-line of the published papers in this category is given in Fig. 6 . The papers can be grouped into four areas which are discussed below.

The first group is made up of papers D10 and D11 which represent original contributions to the field. Although MCT techniques were not directly applied to these papers, they do represent the initial work in applying analytical redundancy to the DIA of sensor failures.
The second group of papers is related by the application of results to the F100 engine. In the highlighted paper $\mathrm{D} 2$, and the closely related papers D1 and D3, a three part program is described. The program consisted of 1) a careful definition of the extent and criticality of the sensor failure problem, 2) a competitive comparison of five different DIA concepts, and 3 ) a detailed evaluation of the best concept using a digital F100 engine simulation. The best concept consists of range checks for the detection and isolation of "hard" failures and a weighted sum of squared residuals test to detect "soft" failures. "Soft" failure detection is followed by hypothesis testing of filter residuals to isolate the soft failure. Failures are accommodated by reconfiguring a Kalman filter to produce estimates of all sensor outputs based upon the set of available, or unfailed, sensor outputs. The work of D8, although independent, did serve as partial background for the study of D2. In D14 a failure sensitive filter approach was applied to the DIA problem for the F100 engine. Detection and isolation was accomplished by associating the directions of measured residual vectors with a set of known direction vectors associated with the various system components. In 015 a real-time microprocessor-based F100 engine simulation is used to construct fan turbine inlet temperature in the accommodation of thermocouple failures.

The next group of papers is related by application of results to the QCSEE. Important and highlighted work here was accomplished by Corley and Spang in D6 and D7 under NASA's QCSEE program. This work is also sometimes referred to as FICA (Failure Indicating and Corrective Action). Here a simplified QCSEE simulation and fixed gain extended Kalman filters provide, to the control, estimates of the state based upon available sensor outputs. Failures are detected and isolated by simple range checks on the filter residuals since the residual elements were assumed independent. In the highlighted work of D4 and the related papers D5 and D12, a Generalized Likelihood Ratio approach was taken to the detection and isolation of sensor failures. The resultant algorithm was applied to a QCSEE simulation to evaluate its usefulness. Finally, in 013 the effects of mismatch between the plant and the model (which is used to generate the residuals) on sensor failure detection is assessed both analytically and by application to a QCSEE example. A simple procedure based upon Student's " $t$ " distribution is presented to detect and remove the effect of this model mismatch.

The final group of papers (D16 and highlighted paper D9) represent the first application of modern estimation techniques to the DIA problem for turbine engines. In both papers, a Bayesian hypothesis testing approach was studied for the detection of sensor failures. This technique required statistical information generated by a bank of Kalman filters which also reconstructed the failed sensor outputs.

\section{Others}

This category describes those remaining papers that did not fall conveniently into any of the previously discussed categories. The time-line for this category is given in Fig. 7. Although, this is a miscellaneous category some grouping is possible, as described below. 
The first group consists of those papers whose results were applied to an F100 engine model. These include papers $01,03,04,06$, and 07 which used the F100 theme problem example of the 1977 NEC Forum. This work includes the adaptive control approaches of 01 and 07, the state space approaches of 04 and 06 , and the optimization approach of 03 . Additionally, in the highlighted paper 09, a model following adaptive control was applied to a full nonlinear simulation of an advanced technology turbof an engine (similar to the F100 engine). The adaptive control law was designed using Liapunov's direct method and applied to the multivariable (two input) simulation.

The second group includes three papers that attempt to improve the performance of an engine relative to a performance criterion. In the case of papers 05 and 011 , the performance criterion is the minimization of thrust specific fuel consumption. In 05 a sequential univariate search technique was applied to an F100/F401 engine. This technique was selected because of its minimal storage and calculation time requirements. In $\mathrm{D} 11$, four advanced optimization techniques (including conjugate gradient and conjugate direction search techniques) were compared when applied to the QCSEE engine. In the highlighted paper 012 Teren developed a new computer algorithm based upon nonlinear programming. This new algorithm was applied to a model of the F100 engine to generate open-loop, minimum-time acceleration control trajectories.

The final group has no real common denominator and includes the final three papers. In the highlighted paper 02, Beattie designed a multivariable engine control for a variable cycle engine using traditional (i.e. not MCT) methods. This paper is included as a point of reference for comparison of controls designed by traditional methods with those designed by MCT. Paper 08 develops an analytical assessment procedure to determine the importance of control variables in a multivariable system. The assessment is based upon a modal interpretation of multivariable system dynamics and is applied to an F100 engine model. Finally, paper 010 discusses some frequency domain and algebraic methods for the design of turbine engine controls.

\section{Present Activities}

At the present time there are a number of ongoing activities in propulsion control design using MCT. These activities include government sponsored $R a D$, industry sponsored $R a D$, and some academic endeavors. This paper will not discuss industrysponsored activities since they are in most cases, proprietary. With respect to government sponsored programs, emphasis will be placed on those sponsored by NASA, plus a brief discussion of an Air Forcesponsored program.

\section{NASA Lewis Programs}

The present Lewis programs are in the technology areas of 1) frequency domain control design, 2) sensor failure detection, 3 ) computer-aided control design, and 4) plant modeling.

Frequency Domain Design. The F100 engine operating point linear models, developed under a number of previous programs will serve as the basis of a frequency domain multivariable control design for that engine. Computer programs developed under a Lewis grant (Ref. F7) are being used to accomplish a Multivariable Nyquist Array (MNA) design. The control gains and compensators will be used with selected portions of the final F100 MVC (LQR) design to accomplish a complete control system. The complete MNA based control will then be operated with the F100 digital simulation to compare MNA performance against that of the LQR design. The objective is to gain insight into the design merits of MNA in terms of simplicity and ease of achieving a solution.

Sensor Failure Accommodation (DIA). During the current calendar year, Lewis intends to further refine the DIA designs discussed earlier. The refinements include: 1) improving the accuracy of the engine models throughout the flight envelope, 2) refining and upgrading the DIA algorithm design for the F100 such that a thorough evaluation of its merits can be conducted, and 3 ) to conduct a thorough and rigorous evaluation of the upgraded DIA algorithm using the Digital F100 engine simulation configured with the LQR-based multivariable control. Also, Lewis continues to sponsor research at Purdue University studying the effect and minimization of model mismatch errors in DIA algorithms.

Computer-Aided Design. Final touches are now being added to a user's manual report for a computer-aided control design package called AESOP. The package, developed at Lewis, solves multivariable control problems using LQR design methods. The program has been configured for ease of use from a time shared terminal.

Plant Modeling. Lewis is sponsoring research at the University of Notre Dame concerned with the generation of simplified nonlinear models for turbine engines. The methods being investigated generate a wide-range nonlinear analytical model which replaces a set of linear models constrained to small neighborhoods about particular operating points. In the future, nonlinear models will serve as a foundation for further studies in nonlinear control design methods.

\section{AFWAL Sponsored Activities}

The AFWAL has sponsored an engine control design effort involving Detroit-Diesel Allison (DDA), Systems Control Technology (SCT), and the Energy Controls Division of Bendix. DDA has generated a simulation for the DDA ATEGG engine, plus linear model representations and performance criteria. SCT is using that information to design an LQR-type control which will be enhanced with sensor failure detection logic and possibly some adaptive features. Bendix has designed a high speed microprocessorbased control package which will implement the SCT algorithms. The Bendix digital engine control is a flight-weight package design and will be mounted on the ATEGG engine for future evaluation tests. The program differs from the F100 MVC in that the evaluations and experiments will be conducted with realistic flight-quality computer hardware and software. The F100 MVC program used general purpose process-control-type minicomputer hardware. Use of state-of-the-art computer circuitry in a package representative of that needed for operational service greatly enhances the credibility of the control's experimental validation results. 


\section{Future Activities}

This section describes the future work being planned or considered at Lewis in the area of MCT applied to aircraft turbines engines. These future activities will address problems in 1) control design, 2) modeling, and 3) DIA of sensor failures.

\section{Control Design}

Work in this area will emphasize computer-aided design ( $C A D)$ of control systems. The interactive program AESOP will be modified to incorporate stateof-the-art CAD features such as menu-driven input as well as improved graphics. Similar improvements are also planned for the multivariable frequency domain design package used at Lewis. Additionally, participation in the newly-formed IEEE Working Group on Computer-Aided Control System Design is planned to help direct future work in this important area.

In addition to the CAD work, research in control system design using LQR methods will continue. Particular issues that will be addressed relate to the implementation of an $L Q R$ control in a microprocessor, the effect of update interval, and the need for controls designed in the discrete time domain rather than the continuous domain. Also, the knowledge gained in turbine engine control programs such as the F100 MVCS program as well as others will be extended and applied to the integrated control of inlet/airframe/propulsion systems.

Finally, in the control design area, some nonlinear control design techniques will be investigated to determine their applicability to the engine control problem. Specific research topies include heuristic adaptive control, nonlinear feedback control, self-optimizing or performance seeking control, and improved optimal trajectory generation. Many of these nonlinear techniques, however, will require improvements in nonlinear engine modelling before achieving application results.

\section{Engine Modeling}

The phrase "engine modeling" is rather broad, but it is generally agreed that the most significant gains to be made are in this area. One aspect of modeling is the identification of models from data. Emphasis at Lewis will be given to the identification of state-space models for the F100 engine at several operating points using presently available closed-loop, altitude-facility test data. Also planned is the real-time identification of a statespace model with time-varying parameters. These tests will identify real-time updates to the engine model as the engine transitions from one flightpoint to another. Again, closed-loop, altitudefacility, engine test-data will be used in the identification process. This kind of research could eventually result in a self-tuning adaptive engine control. The structure of such a control would be fixed but nominal model parameters within the control structure would be constantly updated based upon real-time knowledge of specific engine dynamics.

Also considered will be the use of nonlinear engine models. Important here will be the develop- ment of appropriate nonlinear engine model structures and the identification of parameters within these model structures. Nonlinear models will be required both for the successful application of nonlinear control design techniques and for the study of grossly nonlinear engine phenomena such as compressor stall and surge.

\section{DIA of Sensor Failures}

Tasks planned in the DIA of sensor failures include an evaluation of the algorithm developed in the F100 DIA program (documented in 02) using a real-time, hybrid-computer F100 engine simulation. This evaluation will be quite extensive so as to define necessary modifications to the algorithm and to fully qualify the microprocessor implementation of the DIA algorithm. Once this evaluation phase is completed, the microprocessor-based algorithm will be demonstrated on an F100 engine in the NASA Lewis altitude test facility. Some additional effort in designing DIA algorithms that are robust or insensitive to inevitable model mismatch errors is also being considered. Finally, a hierarchical approach to sensor-failure DIA incorporating advanced nonlinear filtering techniques is being considered.

\section{Concluding Remarks}

The research accomplishments discussed in this paper show that MCT has established a role in the design process of controls for advanced aircraft turbine engines. Organized, systematic methods for designing turbine engine control laws have been demonstrated, using both time and frequency domain techniques. A multivariable control design using LQR methods has been experimentally validated under the F100 MVCS program. Theoretical techniques such as model parameter identification, state estimation, and analytical redundancy for failure accommodation have all been successfully applied to the turbine engine problem. Future efforts in applying MCT to aircraft turbine engine controls will include: experimental validation of the use of analytical redundancy for sensor failure DIA. refinement of present CAD programs for improved engine control mode selection, and development of direct nonlinear control design techniques.

In summary, MCT has provided and will continue to provide the engine control system designer with powerful tools which he can use to deal with the many problems associated with the control of advanced aircraft turbine engines.

\section{References - General}

G-1 Athans, M. and Falb, P.L.; Optimal Control - An Introduction to the Theory and its Application. New York. McGraw Hill, 1965.

G-2 D'Azzo, J.J. and Houpis, C.H.; Feedback Control System Analysis and Synthesis. New York. McGraw Hill, 1960.

G-3 IEEE Transactions on Automatic Control; Special Issue on the Linear Gaussian Estimation and Control Problem. Vol. AC-16, No. 6 December, 1971. 
G-4 Kalman, R.E.; On the General Theory of Control Systems. 1st IFAC Congress, Moscow, 1960, pp. 481-492.

G-5 MacFarlane, A.G.J. and Belletrutti, J.J.; The Characteristic Locus Design Method. Automatica, Vo 1. 9, No. 5, Sept. 1973, pp. 575-588.

G-6 Raven F.H., Automatic Control Engineering, New York. McGraw Hill, 1961.

G-7 Rosenbrock, H.H., Design of Multivariable Control Systems Using the Inverse Nyquist Array. Proceedings of the IEE, November 1969.

\section{References - Linear Quadratic Regulator Techniques}

L-1 Adams, R.J., DeHoff, R.L., and Hall, W.E.: Modeling and Instrumentation Requirements for Multivariable Control of the F100 Turbof an Engine. Presented at the AIAA/SAE 13th Propulsion Conference, Orlando, Florida, July, 1977; AIAA paper No. 77-834.

L-2 Akhter, M.M., Rock, S.M., and DeHoff, R.L.: Trajectory Generation Techniques for Multivariable Control of Aircraft Turbine Engines. Proceedings of the Asilomar Conference on Circuits, Systems and Computers, Pac if ic Grove, CA, November 1978.

L-3 Beattie, E, and Spock, W.: Application of Multivariable Optimal Control Techniques to a Variable Area Turbine Engine. Proceedings of the 1976 Joint Automatic Control Conference, Purdue University, Lafayette, Indiana, July 27-30, 1976.

L-4 Beattie, E.C.: Design of a Multivariable Integrated Control for a Supersonic Propulsion System. 1979 Propulsion Controls Symposium, NASA CP-213, Cleveland, Ohio, May 1979.

L-5 Bowles, R.J.: Sub-0ptimal Control of a Gas Turbine Engine. AD-77852, Master of Science Thesis, AF Institute of Technology, Wright Patterson AFB, Ohio, December 1973.

L-6 Chung, W., and Holley, W.E.: Quasi Triangular Decomposition Applied to the Linearized Control of a Turbof an Engine - Further Results. Proceedings of 1979 JACC, pp. 360-365, June 1979.

L-7 DeHoff, Ronald L.; and Hall, W. Earl, Jr.: Multivariable Control Design Principles with Application to the F100 Turbofan Engine. Proceedings of the 1976 Joint Automatic Control Conference, June 1976, pp. 113-116.

L-8 DeHoff, Ronald L.; and Hall, W. Earl, Jr.: Design of a Multivariable Controller for an Advanced Turbofan Engine. Proceedings of the 1976 IEEE Conference on Decișion and Control, IEEE, Dec. 1976, pp. 1002-1008.

L-9 DeHoff, R.L.; and Hall, W.E.: Jet Engine Systems Modeling-State Space Techniques and Modeling for Control. Advances in Control and Dynamic Systems, Vol. XIV, C.T. Leondes, Editor, Ac ademic Press, New York, N.Y., 1977.

L-10 DeHoff, R.L.,; Hall, Jr.; W. E. Adams, R.J.; and Gupta, N.K.: F100 Multivariable Control Synthesis Program. Vols. I and II, AFAPL-TR-77-35, June 1977.

L-11 DeHoff, R.L.; and Hall, W.E.: A Turbofan Engine Controller Utilizing Multivariable Feedback. Presented at the 1976 IFAC Multivariable Technology Symposium, Fredricton. New Brunswick, Canada, July 1977.

L-12 DeHoff, R.L.; and Rock, S.M.: Multivariable Control Design Principles Applied to a Variable
Cycle Turbofan Engine. Procedings of the Asilomar Conference on Circuits, Systems, and Computers, Pacific Grove, California, November 1978.

L-13 DeHoff, R.L.; and Hall, W.E.,Jr.: Optimal Control of Turbine Engines. ASME Winter Annual Meeting, San Francisco, California, Dec. 10-15, 1978.

L-14 DeHoff, R.L.; and Hall, W.E., Jr.: Multivariable Quadratic Synthesis of an Advanced Turbofan Engine Controller, Journal of Guidance and Control. Vol. I, No.2, pp. 136-142, Mar.-April 1978.

L-15 DeHoff, R.L.; and Hall, W.E., Jr.: Optimal Control of Turbine Engines. Journal of Dynamic Systems, Measurements, and Controls, Vol. 101, June 1979, pp. 117-126.

L-16 Adams, R.J.; DeHoff, R.L.; Rock, S.; and Hall, W.E.,Jr.: Control Aspects of the F100 Altitude Demonstration of the Multivariable Control System. Systems Control, Inc. (Vt), AFWAL-TR-80-2010, March 1980.

L-17 Elliott, J.G.; Seitz, W.R.: Application of Modern Control Theory to the Design of Integrated Airframe/Engine Control Systems. The Bendix Corp., Technical Report BRL/TR-75-7669, 1975.

L-18 Froriep, R.; Joos, D; and G. Kreisselmeier, G.: Optimal Open Loop Compensator Combined with Riccati Feedback Compensation Control System Design Applied to the Turbofan Engine Control. in: Alternatives for Linear Multivariable Control, M.K. Sain, J.L. Peczkowski, and J.L. Melsa, Eds. Chicago: National Engineering Consortium, 1978.

L-19 Hackney, R.D.; Miller, R.J.; Small, L.L.: Engine Criteria and Models for Multivariable Control System Design. in: Alternatives for Linear Multivariable Control, M.K. Sain, J.L. Peczkowski, and J.L. Melsa, Eds. Chicago: National Engineering Consortium, 1978.

L-20 Harvey, C.A.; Stein, G.: Linear Multivariable Control Design Based On Asymptotic Regulator Properties. in: Alternatives for Linear Multivariable Control, M.K. Sain, J.L. Peczkowski, and J.L. Melsa, Eds. Chicago: National Engineering Consortium, 1978.

L-21 Holley, W.E.: Quasi-Upper Triangular Decomposition Applied to the Linearized Control of a Turbof an Engine--Preliminary Results. in: Alternatives for Linear Multivariable Control, M.K. Sain, J.L. Peczkowski, and J.L. Melsa, Eds. Chicago, National Engineering Consortium, 1978.

L-22 Lehtinen, Bruce; and Soeder, James F.: F100 Multivariable Control Synthesis Program: A Review of Full-Scale Engine Altitude Tests. 1979 Propulsion Controls Symposium, NASA CP-213, Cleveland, Ohio, May 1979.

L-23 Lehtinen, B.; DeHoff, R.L.; and Hackney, R.D.: Multivariable Control Altitude Demonstration on the F100 Turbofan Engine. AIAA Paper No. 79-1204, Presented at Fifteenth Joint Propulsion Conference, Co-sponsored by AIAA, SAE, and ASME, Las Vegas, Nevada, June 18-20, 1979.

L-24 Lehtinen, B.; DeHoff, R.L.; and Hackney, R.D.: Multivariable Control Altitude Demonstration on the F100 Turbofan Engine, Journal of Guidance and Control. Vol. IV, No. 1, Jan-Feb 1981, pp. 50-58. 
L-25 Lehtinen, B.; Soeder, J.; Costakis, W.; and Seldner, K.: Altitude Tests of a Multivariable Control for the F100 Turbofan Engine. NASA TR E-610.

L-26 Merrill, Walter C.: An Application of Modern Control Theory to Jet Propulsion Systems. NASA TMX-71726, May 1975.

L-27 Merrill, Walter C.: Design of Turbofan Engine Controls Using Output Feedback Regulator Theory. 1977 Joint Automatic Control Conference, San Francisco, California, Session TA25, June $22-24,1977$. A1so NASA TM X-73622.

L-28 Merrill, Walter C.: Output Feedback Regulator Design for Jet Engine Control Systems. in: Alternatives for Linear Multivariable Control. National Engineering Consortium, Chicago, Illinois, 1978 . also NASA TM-73776.

L-29 Michael, Gerald J.; and Farrar, Florence A.: An Analytical Method for the Synthesis of Nonlinear Multivariable Feedback Control. UARL-M941338-2, United Aircraft Research Labs. (AD-762797), 1973.

L-30 Michael, Gerald J.; and Farrar, Florence A.: Development of Optimàl Contro? Modes for Advanced Technology Propulsion Systems. UARL-N911620-2, United Aircraft Research Labs. (AD-775337), 1974.

L-31 Miller, Ronald J.; and Hackney, Ronald D.: F100 Multivariable Control System Engine Models/Design Criteria. FR-7809, Pratt and Whitney Aircraft Group. (AFAPL-TR-76-75, AD-A033532), November 1976.

L-32 Rock, S.M.; and DeHoff, R.L.: Variable Cycle Engine Multivariable Control Synthesis: Interim Report - Control Structure Definition. AFAPL-TR-79-2043, February 1979.

L-33 Rock, S.M.; and DeHoff, R.L.: Applications of Multivariable Control to Advanced Aircraft Turbine Engines. 1979 Propulsion Controls Symposium, NASA CP-213, Cleveland, Ohio, May 1979.

L-34 Rock, S.M.; and DeHoff, R.L.: Optimal Output Feedback for Systems Having Direct Feed Through of Control. Proceedings of the 1979 Joint Automatic Control Conference, June 1979.

L-35 Sain, M.K.: The Theme Problem. in: Alternatives for Linear Multivariable Control, M.K. Sain; J.L. Peczkowski, and J. L. Melsa, editors. Chicago: : National Engineering Consortium, 1978, pp. 20-30.

L-36 Skira, C.A.; and DeHoff, R.L.: A Practical Approach to Linear Model Analysis for Multivariable Turbine Engine Control Design. in: Alternatives for Linear Multivariable Control, M. Sain, J. Peczkowski, J. Melsa, Eds.

Chicago: National Engineering Consortium, 1978, pp. 31-46.

L-37 Slater, G.L.: Optimal Controls for Advanced Turbofan Engines.

Proceedings of the 1976 JACC, July, 1976.

L-38 Soeder, J.F.; and Cwynar, D.S.: Computer Implementation of the F100 Multivariable Control Logic. Proposed NASA TP , 1982

L-39 Stone, C.R.; et al.: Turbine Engine Control Synthesis, Vo. I. Honeywell F0164-FR-Vol-1, Systems and Research Division.

(AFAPL-TR-75-14-Vol-1, ADA014229), 1975.

L-40 Szuch, J.R.; Skira, C.; and Soeder, J.F.: Evaluation of an F100 Multivariable Control Using a Real-Time Engine Simulation. NASA TMX-73648, July 1977.

L-41 Szuch, J.R.; Soeder, J.F.; Seldner, K.; and Cwynar, D.S.: F100 Multivariable Control
Synthesis Program-Evaluation of a Multivariable Control Using a Real-Time Engine Simulation," NASA TP 1056, October 1977.

L-42 Wanger, R.; Corley, R.; and Anderson, R.: Variable Cycle Engine Multivariable Control Synthesis. Phase I General Electric Interim Technical Report, August, 1978.

L-43 Weinberg, Marc S.: A Multivarible Control for the F100 Engine Operating at Sea-Level Static. ASD-TR-75-28, Aeronautical Systems Division, Wright Patterson Air Force Base, 1975.

\section{References - Frequency Domain Techniques}

F-1 Brown, H.: V/STOL Propulsion Control Analysis. Phase I - Final Report - NAS3-2205, February 1981.

F-2 Gejji, R.R.; and Sain, M.K.: Applications of Polynomial Techniques to Multivariable Control of Jet Engines. Preprints, of 4th IFAC Symposium on Multivariable Technological Systems, Fredericton 1977, PP. 421-429.

F-3 Hofmann, L.G.; Teper, G.L.; and Whitbeck, R.F.: Application of Frequency Domain Multivariable Control Synthesis Techniques to an Il lustrative Problem in Jet Engine Control. in: Alternatives for Linear Multivariable Control, M.K. Sain, J.L. Peczkowski, and J.L. Melsa, eds. Chicago: National Engineering Consortium, 1978.

F-4 Kouvaritakis, B.; and Edmunds, J.M.: The Characteristic Frequency and Characteristic Gain Design Method for Multivariable Feedback Systems, in: Alternatives for Linear Multivariable Control, M.K. Sain, J.L. Peczkowski, and J.L. Melsa, eds. Chicago: National Engineering Consortium, 1978, pp. 299-246.

F-5 Leininger, G.G.: Diagonal Dominance for the Multivariable Nyquist Array Using Function Minimization, Final Report, NASA Grant 3063, University of Toledo Report TR 7701, May 1977.

F-6 Leininger, G.G.: The Multivariable Nyquist Array - The Concept of Dominance Sharing. in: Alternatives for Linear Multivariable Control, M.K. Sain, J.L. Peczkowski, and J.L. Melsa, eds. Chicago: National Engineering Consortium, 1978.

F-7 Leininger, G.G.: Multivariable Compensator Design Using Bode Diagrams and Nichols Charts. IFAC Symposium on Computer Aided Design of Control Systems. Zurich, 1979.

F-8 Leininger, G.G.: Multivariable Nyquist Array Method With Application to Turbofan Engine Control. 1979 Propulsion Controls Symposium, NASA CP-213, Cleveland, Ohio, May 1979.

F-9 Leininger, G.G.: Diagonal Dominance for Multivariable Nyquist Array Methods Using Function Minimization. Automatica, Vol. 15, pp. $339-345,1979$.

F-10 Leininger, G.G.: "New Dominance Characteristics for the Multivariable Nyquist Array Method," Int. J. Control, Vol. 30, pp. 459-475, 1979.

F-11 Leininger, G.G.: Application of the MNA Design Method to a Nonlinear Turbofan Engine. Final Report - NASA Grant NSG 3171, January 1981.

F-12 MacFarlane, A.G.J.; McMorran, P.D.; Dixon, B.A.; and Hodge, S.S.: Applications of Multivariable Control Techniques to Aircraft Gas Turbines. Conf. on Multivariable Control Systems Design and Application, Sept. 1-3, 1971. 
F-13 McMorran, P.D.: Design of Gas-Turbine Controller Using Inverse Nyquist Method, Proceedings of IEE. Vo. 117, No. 10, October 1970.

F-14 Peczkowski, J.L.; Sain, M.K.: Linear Multivariable Synthesis with Transfer Functions. in: Alternatives for Linear Multivariable Control, M.K. Sain, J.L. Peczkowski, and J.L. Melsa, eds. Chicago: National Engineering Consortium, 1978, pp. 1-37.

F-15 Peczkowski,J.L.: Multivariable Synthesis with Transfer Functions, 1979 Propulsion Controls Symposium, NASA CP-213, Cleveland, OH, May 1979.

F-16 Peczkowski, J.L.; Sain, M.K.; Leake, R.J.: Multivariable Synthesis with Inverses. Proceedings of 1979 JACC, pp. 375-380, June 1979.

F-17 Rosenbrock, H.H.; and Munro, N.: The Inverse Nyquist Array Method, in: Alternatives for Linear Multivariable Control, M.K.Sain, J.L. Peczkowski, and J.L. Melsa, eds. Chicago: National Engineering Consortium, 1978, pp. 101-137.

F-18 Sain, M.K.; Leake, R.J.; Basso, R.; Gejji, R.; Maloney, A.; and Seshadri, V.: Alternative Methods for the Design of Jet Engine Control Systems. Proceedings of the 1976 Fifteenth Joint Automatic Control Conference, July 1976, pp. 133-142.

F-19 Sain, M.K.; and Schafer, R.M.: Alternatives for Jet Engine Control. 1979 Propulsion Controls Symposium, NASA CP-213, Cleveland, Ohio, May 1979. May 1979.

F-20 Schafer, R.M.; Sain, M.K.: Input Compensation for Dominance of Turbofan Models. in: Alternatives for Linear Multivariable Control, M.K. Sain, J.L. Peczkowski, and J.L. Melsa, editors. Chicago: National Engineering Consortium, 1978, pp. 156-169.

F-21 Schafer, R.M.; and Sain, M.K.: "Frequency Dependent Precompensation for Dominance in a Four Input/Output Theme Problem Model," Proceedings Eighteenth Joint Automatic Control Conference, pp. 348-353, June 1979.

F-22 Spang, H.A.: Insight into the Application of the Inverse Nyquist Array Method to Turbofan Engine Control. in: Alternatives for Linear Multivariable Control, M.K. Sain, J.L. Peczkowski, and J.L. Melsa, editors. Chicago: National Engineering Consortium, 1978, pp. 138-155.

References - Identification, Estimation, and Model Reduction

I-1 Baskiotis, C; Raymond, J.; and Rault, A. Parameter Identification and Discriminent Analysis for Jet Engine Mechanical State Diagnosis. 18th IEEE Conf. on Decision and Control, Ft. Lauderdale, FL, Vol. II, December 1979, pp. 658-650.

I-2 DeHoff, R.L.; and Hall, W.E.: System Identification Principles Applied to Multivariable Control Synthesis of the F100 Turbofan Engine. presented at the 1977 Joint Automatic Control Conference, San Francisco, CA, June 1977.

1-3 DeHoff, R.L.: Identification of a STOL Propulsion Plant Model from Flight Data. J. Guidance and Control, Vol. 2, No. 3, May-June 1979, pp. 235-240.

I-4 Leonard, R.G.; and Arnett, E.M.: Engine Identification for Adaptive Control. 1979 Propulsion Controls Symposium, Cleveland, Ohio, NASA CP-213, May 1979.
I-5 Farrar, F.A.; and Michael, G.J.: Large-Signal Estimation for Stochastic Nonlinear Multivariable Dynamic Systems. Office of Naval Research Report ONR-CR215-247-1, Arlington, VA, March 1977.

I-6 Merrill, Walter C.: The Application of the Routh Approximation Method to Turbofan Engine Models. 1977 Joint Automatic Control Conference, San Francisco, CA, Session FA28, June $22-24,1977$. NASA TM X-73623.

I-7 Merrill, Walter C.: Multivariable Identification Using Centralized Fixed Modes. NASA CP-2137, 1979, pp. 3-11.

I-8 Merrili, Walter C.; and Leininger, G.: Identification and Dual Adaptive Control of a Turbojet Engine, Int. J. Control, Vol. 34, No. 3, September 1981, pp.529-546.

I-9 Merrill, W.: Identification of Multivariable High Performance Turbofan Engine Dynamics from Closed-Loop Data, NASA TM 82785, Dec. 1981.

I-10 Michael, G.J.; and Farrar, F.A.: Identification of Multivariable Gas Turbine Dynamics From Stochastic Input-Output Data. Annual Tech. Report prepared for Office of Naval Research under Contract N00014-73-C-0281, March 1975. UARL Report R-941620-3.

I-11 Michael, G.J.; Farrar, F.A.: Stochastic Regulation of Nonlinear Multivariable Dynamic Systems. Final Report for period 1 Feb. 1973 through 31 January 1976, Report ONR-CR-215-219-4F.

I-12 Michael, G.J.; and Farrar, F.A.: Estimation and Control of Critical Gas Turbine Engine Variables. 1976 ASME Winter Annual Meeting, Paper WA/AUT-12, Dec. 5, 1976.

I-13 Rault, A; Richalet, J; Barbot, A; Sergenton, J.P.: Identification and Modeling of a Jet Engine. IFAC Symposium on Digital Simulation of Continuous Processes, Gejor, 1971.

I-14 Sahgal, R.K.; McKee, G.T.; Anderson, B.A.; and Hackney, R.D.: Real-Time Estimation in Advanced Turbofan Engines. Proceedings of the 1980 Joint Automatic Control Conference, San Francisco, CA, August 1980.

I-15 Seldner, K; and Cwynar, D.D.: Procedure for Generation and Reduction of Linear Models of a Turbof an Engine. NASA TP-1261, August 1978.

I-16 Szuch, J.R.: Models for Jet Engine Systems Techniques for Jet Engine Systems Modeling. in: Control and Dynamic Systems - Advances in Theory and Applications (C.T. Leondes, ed.) Vol. 14, Academic Press, NY 1978.

I-17 Weinberg, M.S.: Direct Reduction of High Order Systems by State Variable Techniques. ENJE-TM-75-6, Wright Patterson Air Force Base, February, 1975.

I-18 Weinberg, Marc S.: Low Order Linearized Models of Turbine Engines. ASD-TR-75-24, Wright Patterson Air Force Base, July 1975.

References - Detection, Isolation, and Accommodation

D-1 Akhter, M.M.; and Rock S.M.: Evaluation of Sensor Failure Detection, Isolation, and Accommodation Concepts for an Advanced Turbofan Engine. Presented at the Joint Automatic Control Conference, Charlottesville, VA, June 1981.

D-2 Beattie, E.C.; LaPrad, F.F.; McGlone, M.E.; Rock, S.M.; and Akhter, M. M.: Sensor Failure Detection System. NASA CR-165515, August 1981.

D-3 Beattie, E.; and LaPrad, R.: Application Considerations In Advanced Sensor Failure Detection, Isolation and Accommodation Concepts. 
Presented at the 1981 Joint Automatic Control Conference, Charlottesville, VA, June 1981.

D-4 Behbehani, K.: Sensor Failure Analysis and Multivariable Control for Airbreathing Propulsion Systems. Ph.D. Dissertation, University of Toledo, NASA CR-159791, March 1980.

D-5 Behbehani, K.; Leininger, G.G.:

Sensor/Actuator Failure Detection for Turbofan Engines. 1979 Propulsion Controls Symposium, NASA CP-213, Cleveland, OH, May 1979.

D-6 Corley, R.C.; and Spang, H.A.: Failure Detection and Correction for Turbof an Engines. Report 77CRD159, General Electric Corporation Research and Development Schnectady, NY, 1977.

D-7 Corley, R.C.; and Spang, H.A., III: Failure Detection and Correction for Turbofan Engines. Presented at the 1977 Joint Automatic Control Conference, San Francisco, CA, June 1977.

D-8 DeHoff, R.L.; and Hall, W.E.: Advanced Fault Detection and Isolation Methods for Aircraft Turbine Engines. Office of Naval Research Report ONR-CR-215-245-1, February 1978.

D-9 DeSilva, C.W.: Sensor Failure Detection and Output Estimation for Engine Control Systems. MS Thesis, Univ. of Cincinnati, 1976.

D-10 Ellis, S.H.: Self-Corrrecting Control for a Turbofan Engine. Pratt and Whitney Aircraft Report PWA FR-6778, January 1975.

D-11 Hrach, F.J.; Arpasi, D.J.; and Bruton, W.M.: Design and Evaluation of a Sensor Failure Operational Control System for a Digitally Controlled Turbof an Engine. NASA TMX1-3260, Dec. 1975.

D-12 Leininger, G.G.; and Behbehani, K.: Sensor/Actuator Failure Detection and Isolation for Airbreathing Propulsion Systems. Proceedings of the 1980 Joint Automatic Control Conference, San Francisco, CA, August 1980.

D-13 Leininger, G.G.: Model Degradation Effects on Sensor Failure Detection. Proceedings of the 1981 Joint Automatic Control Conference, Charlottesville, VA., June, 1981.

D-14 Meserole, J.S.: "Detection Filters for Fault Tolerant Control of Turbof an Engines, Ph.D. Thesis, Massachusetts Institute of Technology, June 1981.

D-15 Sahgal, R.K.; and Miller, R.J.: Failure Accommodation in Gas Turbine Engines with Application to Fan Turbine In let Tempeature Reconstruction. Proceedings of the 1979 Joint Automatic Control Conference, Denver, C0, pp. 381-386, June 1979.

D-16 Wells, W.R.: Detection of Sensor Failure and Output Reconstruction for Aircraft Controls, AIAA Paper no. 78-4, 1978.

\section{References - Others}

0-1 Aplevich, J.D.: An Application of Model Following Control. Proceedings of the 1979 Joint Automatic Control Conference, Denver, CO, June 1979, pp. 383-398.

0-2 Beattie, Edward, C.: Control Mode Studies for Advanced Variable-Geometry Turbine Engines. Pratt a Whitney Aircraft. Report PWA-5161, (AD-A009169), 1974.

0-3 Cheng, Y.: A Parameter Optimization Method Applied to Engine Control System Design. in: Alternatives for Linear Multivariable Control, M.K. Sain, J.L. Peczkowski, and J.L. Melsa, eds. Chicago: National Engineering Consortium, 1978 .
0-4 Davison, E.J.; and Gesing, W.: The Systematic Design of Control Systems for the Linear Multivariable Servomechanism Problem. in: Alternatives for Linear Multivariable Control, M.K. Sain, J.L. Peczkowski, and J.L. Melsa, eds. Chicago: National Engineering Consortium, 1978.

0-5 Jordan, D.; and Michael, G.J.: Development of Gas Turbine Performance Seeking Logic. ASME Paper No. 78-GT-13. Vol. 100, Journal of Engineering for Power, Oct. 1978.

0-6 Liberty, S.R.; Maynard, R.A.; and Mielke R.R.: Design of a Turbojet Engine Controller Via Eigenvalue/Eigenvector Assignment: A New Sensitivity Formulation: Proceedings of 1979 Joint Automatic Control Conference, June 1979, Pg. 359.

0-7 Mehra, R.K.; Kessel, W.C.; Rault, A.; Richalet, J.; and Papon, J.: Model Algorithmic Control Using IDCOM for the F100 Jet Engine Multivariable Control Design Problem. in: Alternatives for Linear Multivariable Control, M.K. Sain, J.L. Peczkowski, and J.L. Melsa, eds. Chicago: National Engineering Consortium, 1978.

0-8 Michael, G.J.; and Sogliero, G.S.: Key Control Assessment to Linear Multivariable Systems. AFOSR Final Report R76-942042, Jan. 1976.

0-9 Monopoli, R.V.: Model Following Control of Gas Turbine Engines. Proceedings of the 1980 Joint Automatic Control Conference, San Francisco, CA, August 1980.

0-10 Sain, M.K., et al.: Alternative Methods for the Design of Jet Engine Control Systems. Proceedings of the 1976 Joint Automatic Control Conference, July 1976, pp. 133-142.

0-11 Seldner, K.: Performance-Seeking Controls, 1979 Propulsion Controls Symposium. NASA $\mathrm{CP}-213, \mathrm{Cleveland,} \mathrm{OH}$, May 1979.

0-12 Teren, F.: Minimum Time Acceleration of Aircraft Turbofan Engines by Using an Algorithm Based on Nonlinear Programming. NASA TM-73741, June 1977. 


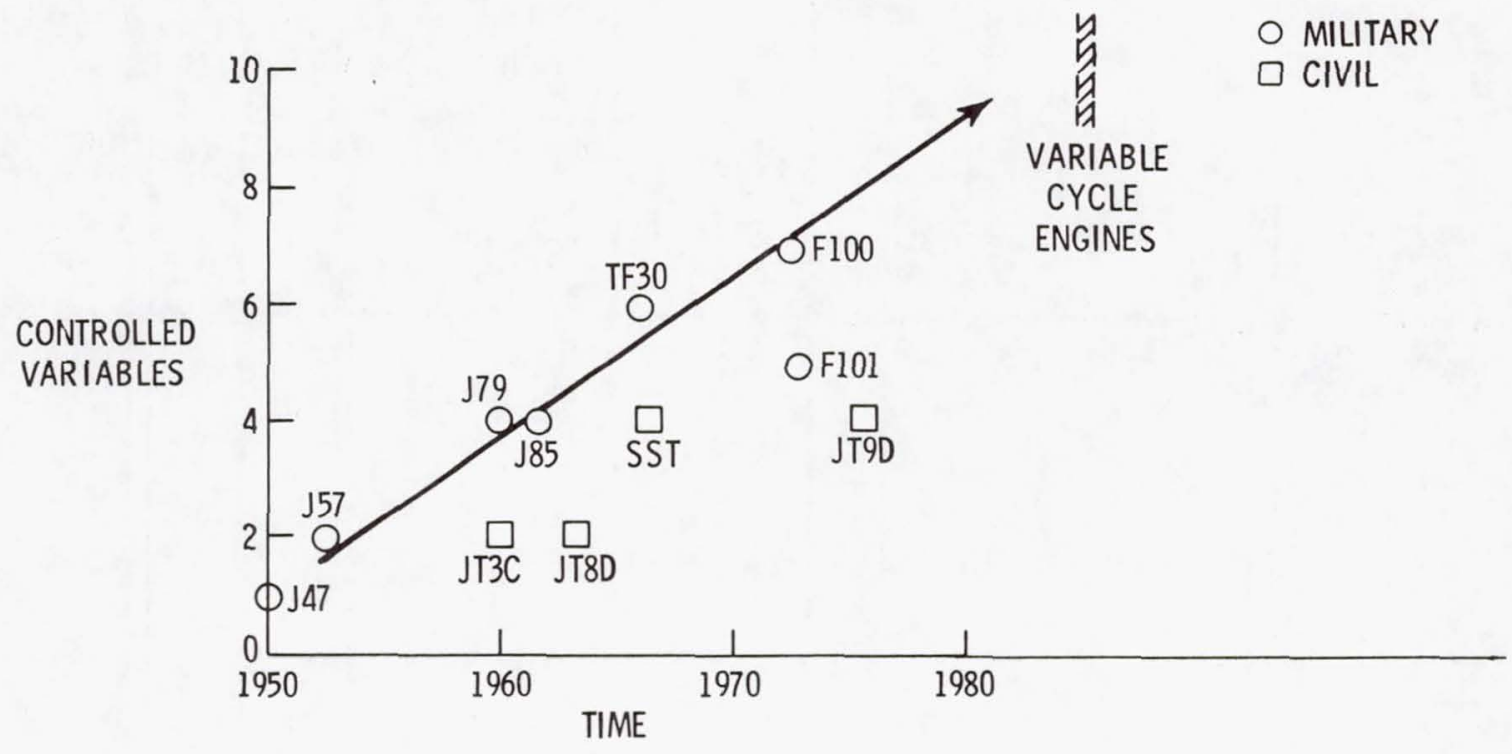

Figure 1. - Trends in control complexity.

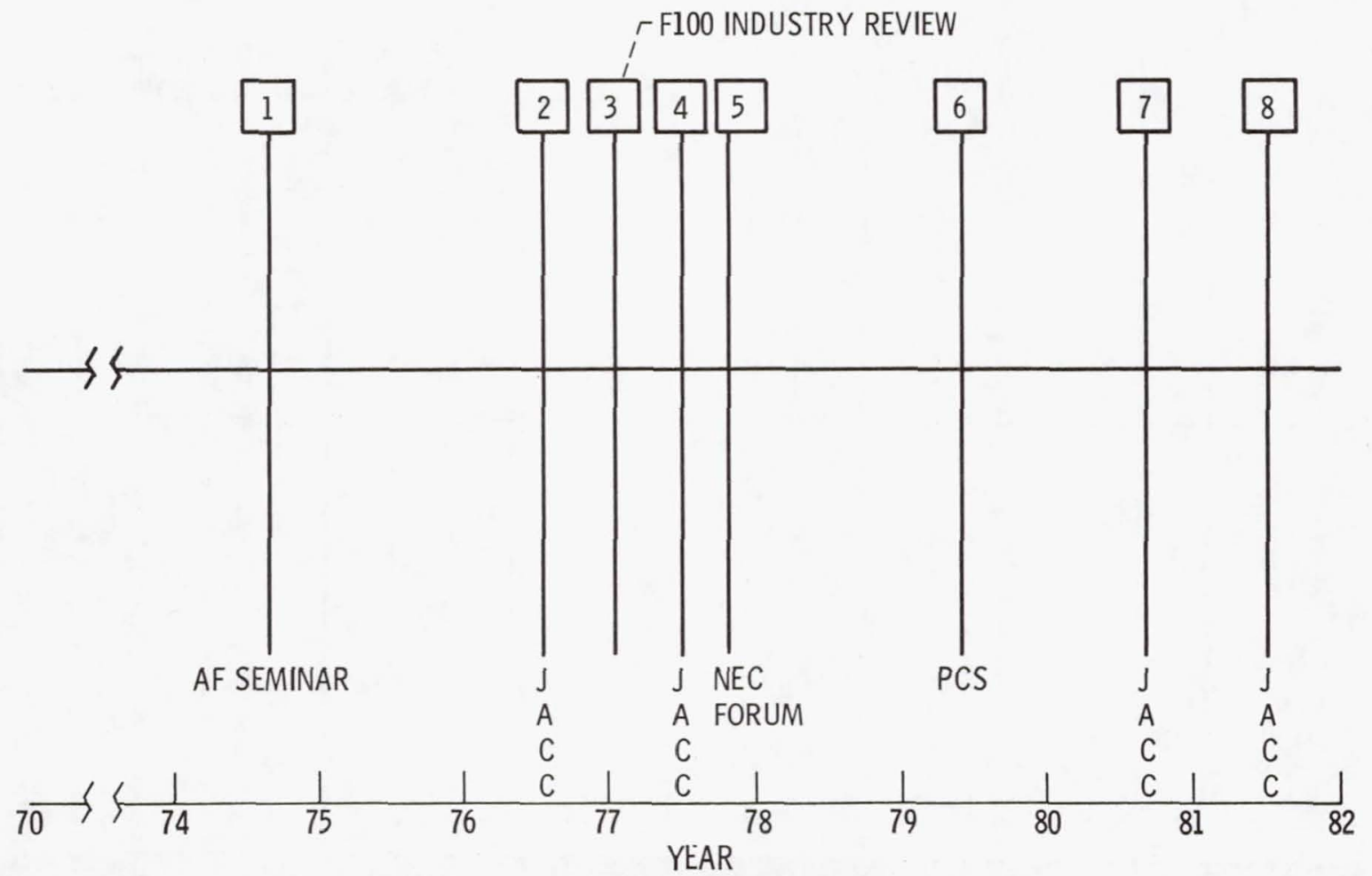

Figure 2. - Time line format with significant events. 


\section{HIGHLIGHTS}

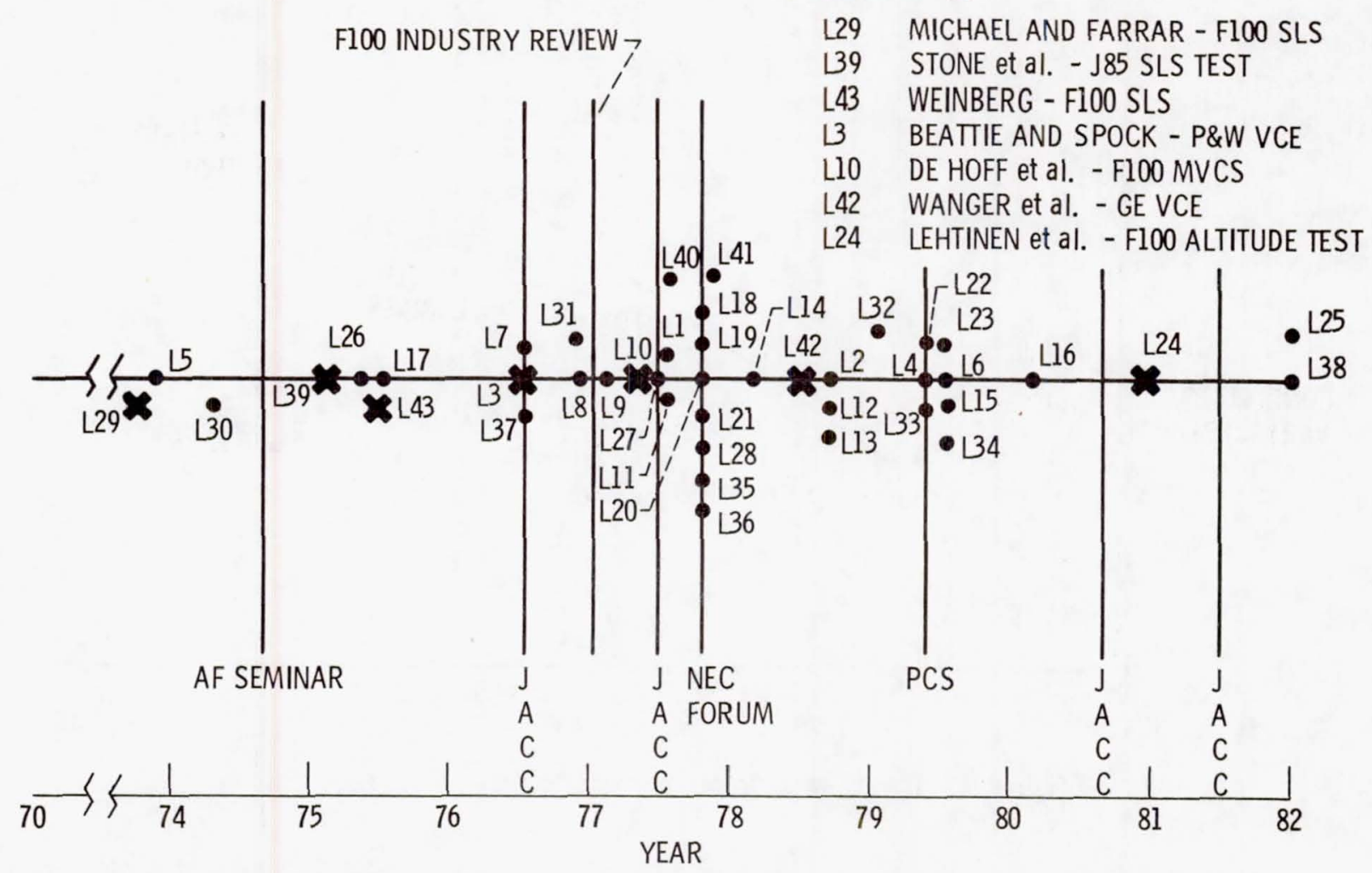

Figure 3. - Papers applying linear quadratic regulator methods to aircraft turbine engine control design.

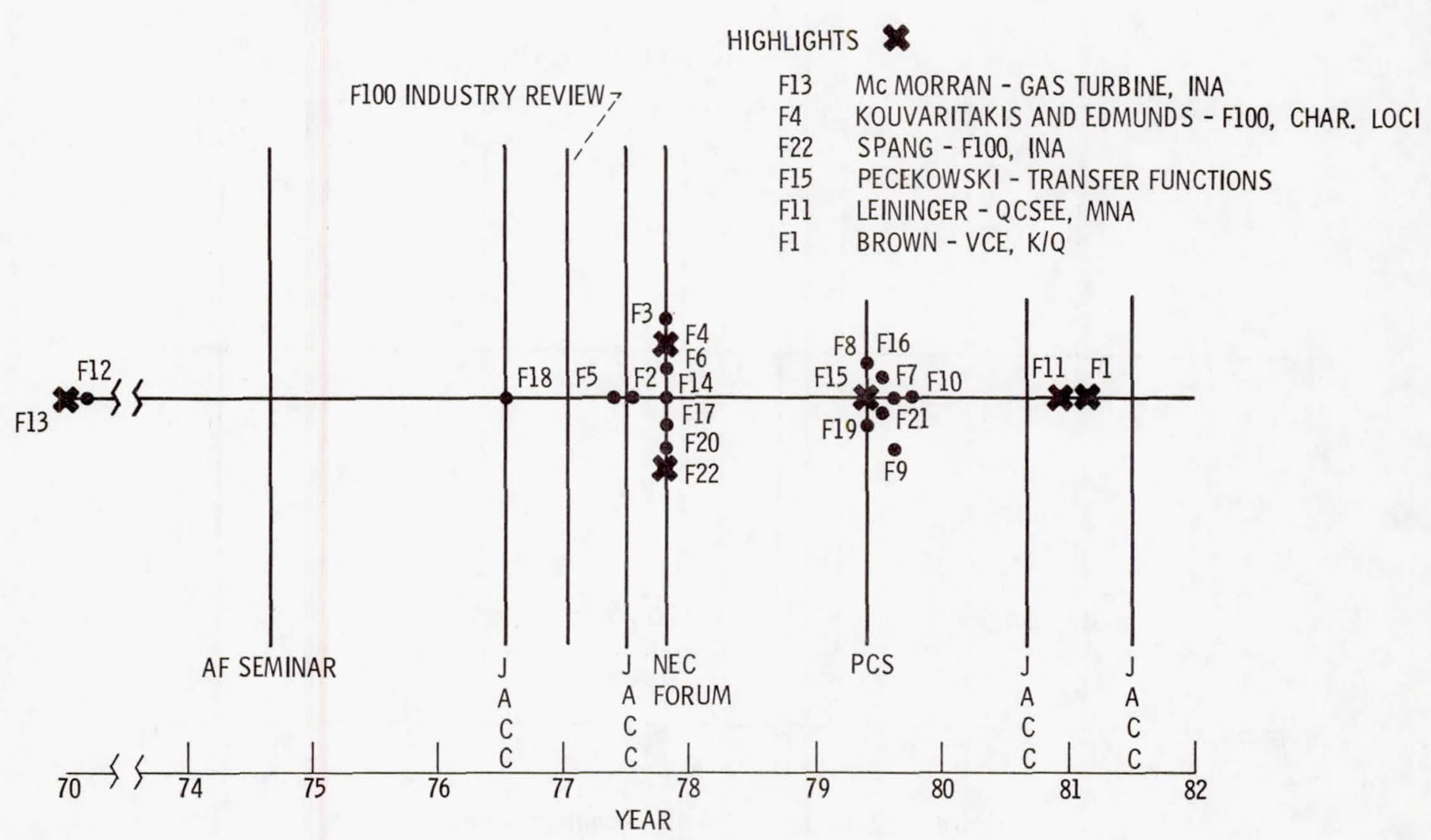

Figure 4. - Papers applying frequency domain design methods to aircraft turbine engine control design. 


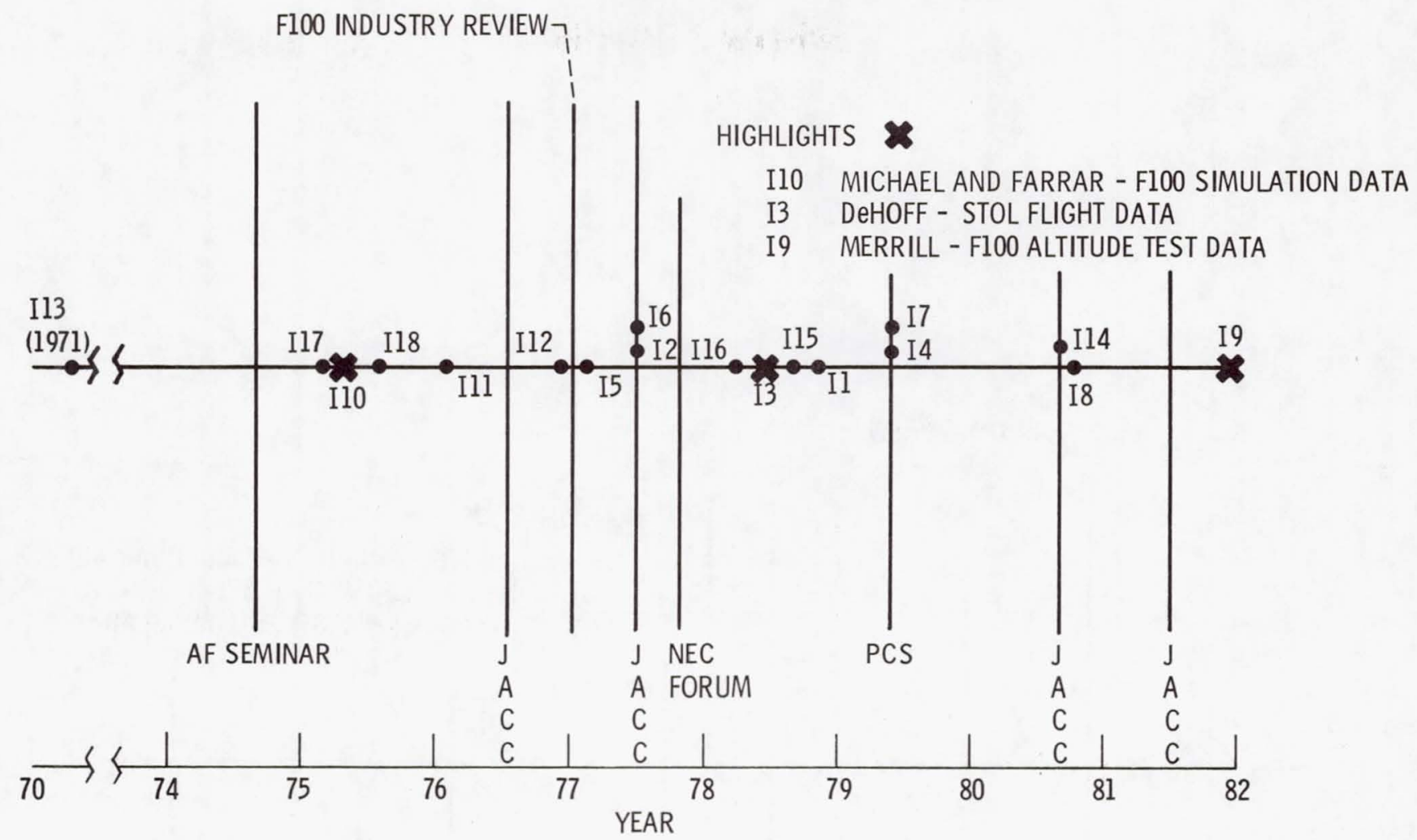

Figure 5. - Papers applying identification, estimation, and model reduction methods to aircraft turbine engines.

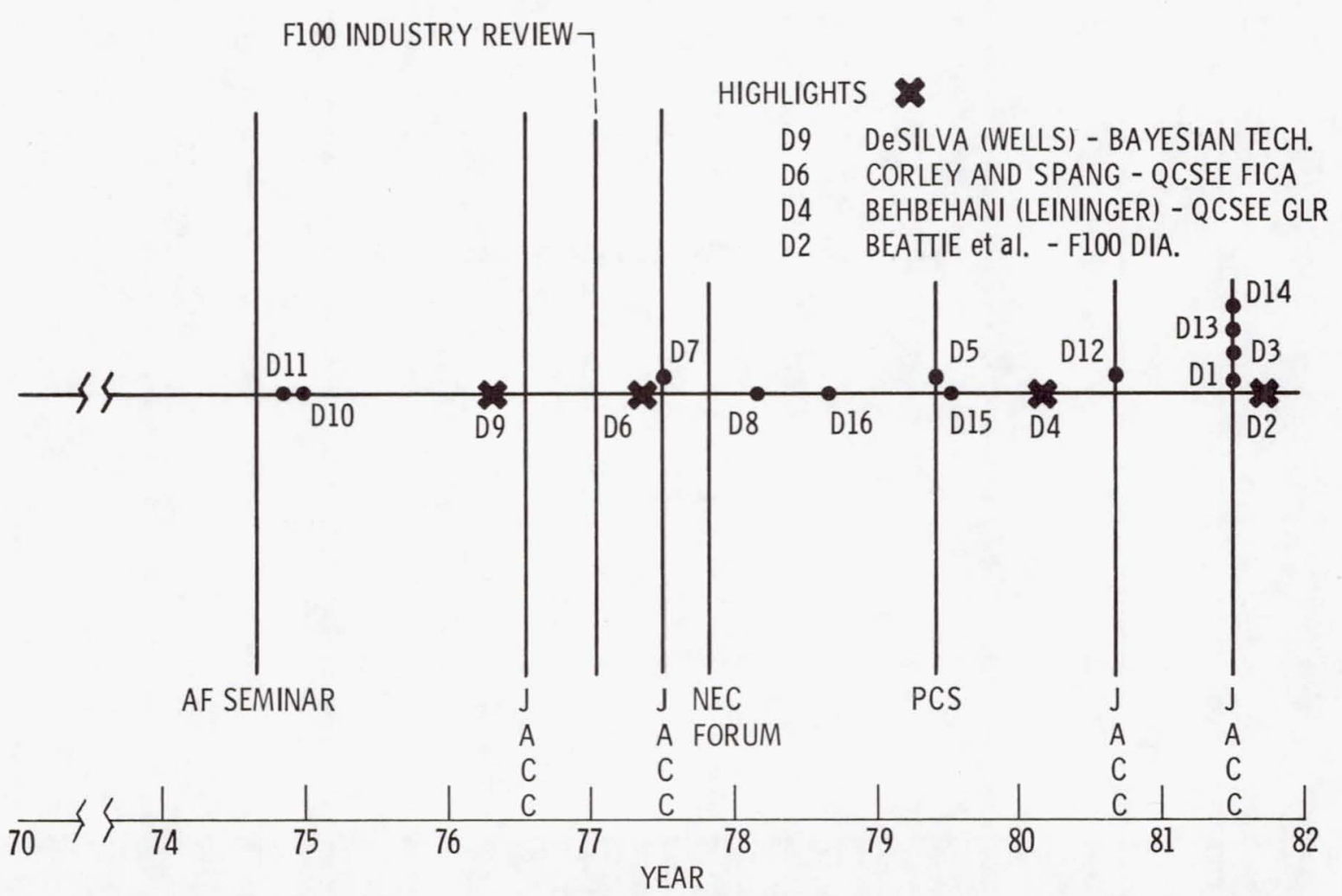

Figure 6. - Papers applying detection, isolation, and accommodation methods to aircraft turbine engines. 


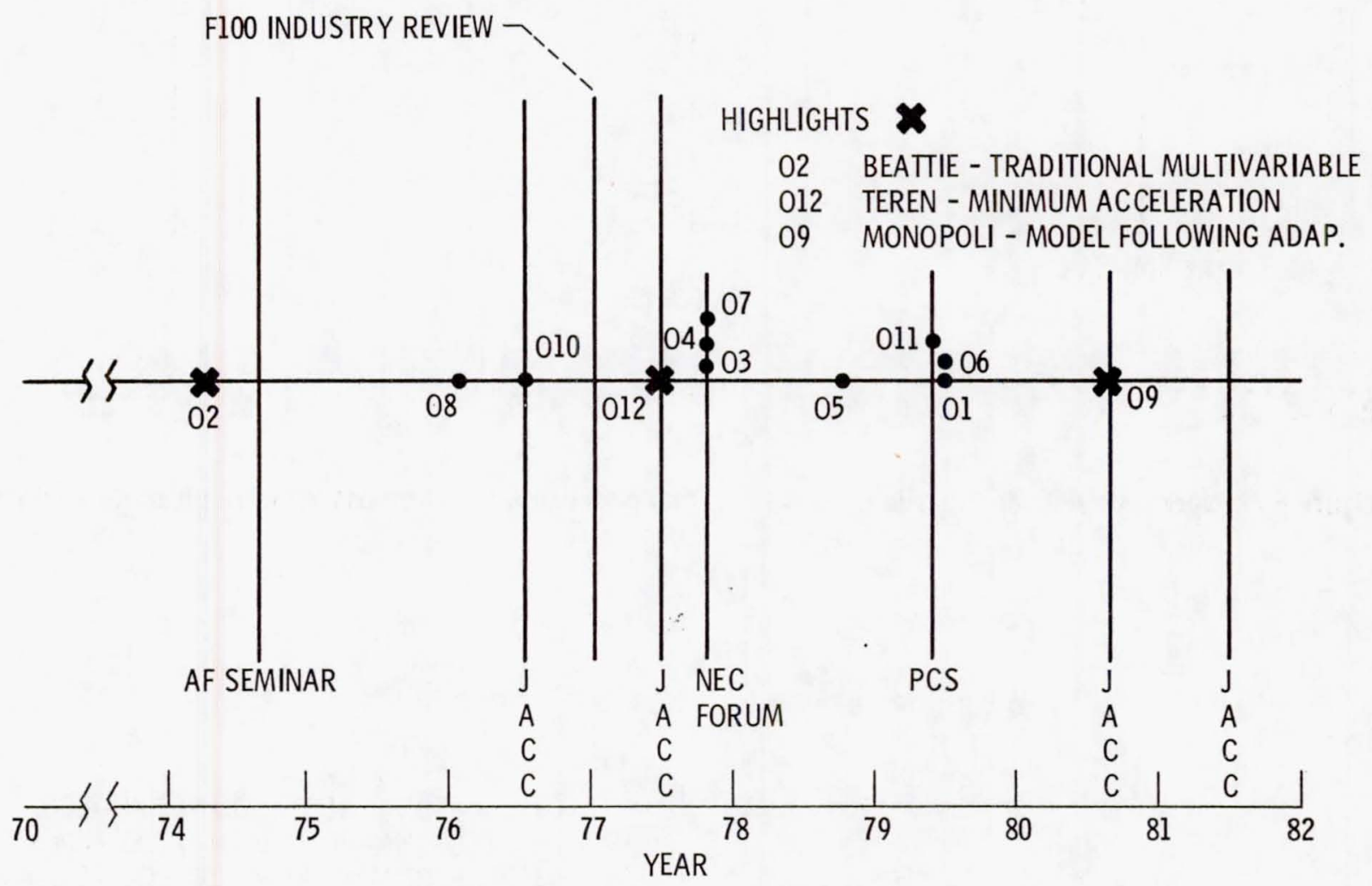

Figure 7. - Miscellaneous (other) papers. 


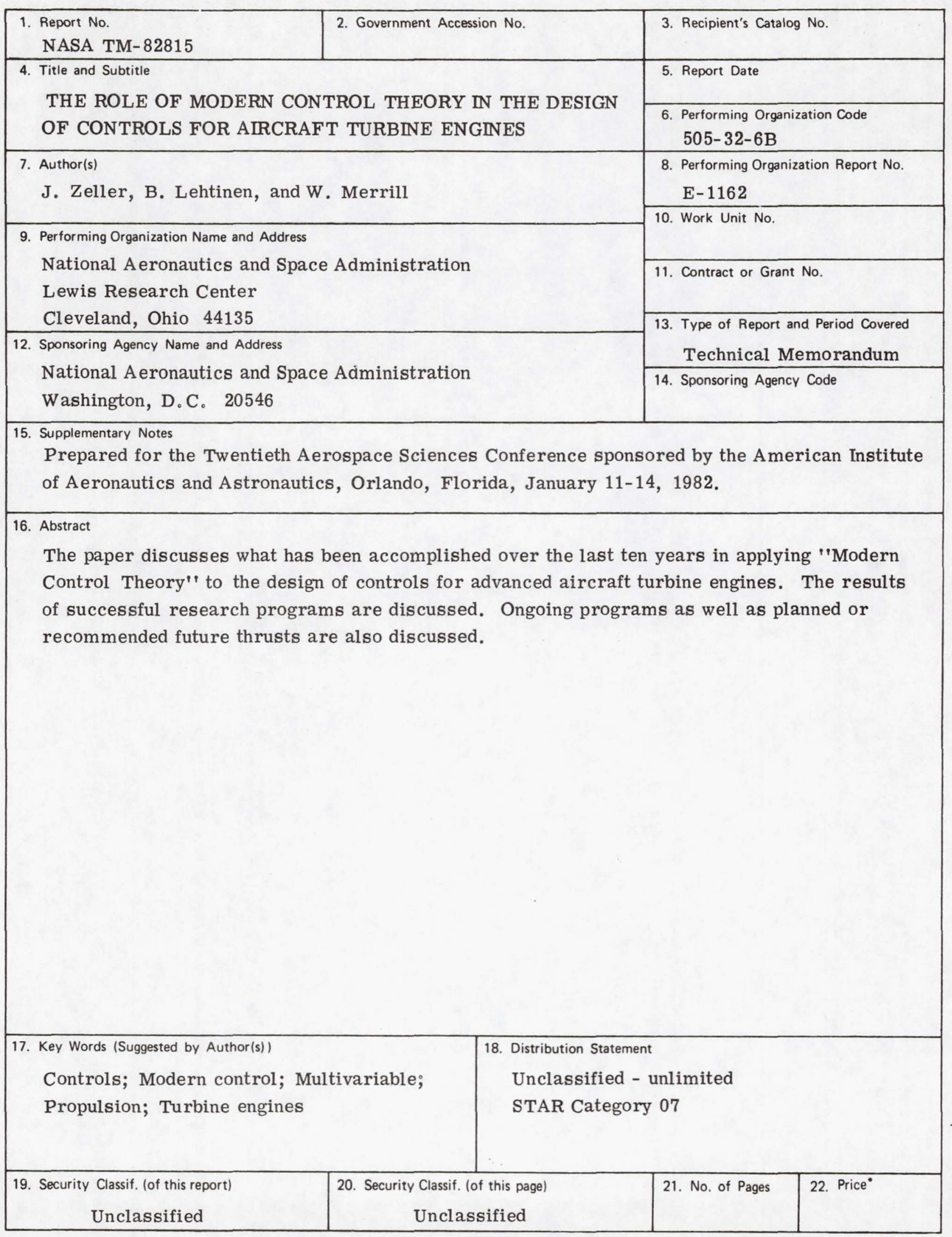

* For sale by the National Technical Information Service, Springfield, Virginia 22161 